\title{
A method of producing genetically manipulated mouse mammary gland
}

Hiroaki Tagaya ${ }^{1,2 \dagger}$, Kosuke Ishikawa ${ }^{3^{*+}} \mathbb{D}$, Yoshito Hosokawa', Shun Kobayashi', Yukino Ueoka', Mayuna Shimada', Yasuko Ohashi ${ }^{1}$, Hirofumi Mikami ${ }^{1}$, Mizuki Yamamoto ${ }^{4}$, Tatsuya Ihara' ${ }^{1}$ Kentaro Kumazawa' ${ }^{1}$, Kosuke Sugihara', Naoki Goshima5,6, Shinya Watanabe ${ }^{6}$ and Kentaro Semba ${ }^{1,6^{*}}$

\begin{abstract}
Background: To obtain a deep understanding of the mechanism by which breast cancer develops, the genes involved in tumorigenesis should be analyzed in vivo. Mouse mammary gland can regenerate completely from a mammary stem cell (MaSC), which enables us to analyze the effect of gene expression and repression on tumorigenesis in mammary gland regenerated from genetically manipulated MaSCs. Although lentiviral and retroviral systems have usually been applied for gene transduction into MaSCs, they are associated with difficulty in introducing long, repeated, or transcriptional termination sequences. There is thus a need for an easier and quicker gene delivery system.

Methods: We devised a new system for gene delivery into MaSCs using the piggyBac transposon vectors and electroporation. Compared with viral systems, this system enables easier and quicker transfection of even long, repeated, or transcriptional termination DNA sequences. We designed gene expression vectors of the transposon system, equipped with a luciferase (Luc) expression cassette for monitoring gene transduction into regenerative mammary gland in mice by in-vivo imaging. A doxycycline (Dox)-inducible system was also integrated for expressing the target gene after mammary regeneration to mimic the actual mechanism of tumorigenesis.

Results: With this new gene delivery system, genetically manipulated mammary glands were successfully reconstituted even though the vector size was $>200 \mathrm{~kb}$ and even in the presence of DNA elements such as promoters and transcription termination sequences, which are major obstacles to viral vector packaging. They differentiated correctly into both basal and luminal cells, and showed normal morphological change and milk production after pregnancy, as well as self-renewal capacity. Using the Tet-On system, gene expression can be controlled by the addition of Dox after mammary reconstitution. In a case study using polyoma-virus middle $T$ antigen (PyMT), oncogene-induced tumorigenesis was achieved. The histological appearance of the tumor was highly similar to that of the mouse mammary tumor virus-PyMT transgenic mouse model.
\end{abstract}

Conclusions: With this system, gene transduction in the mammary gland can be easily and quickly achieved, and gene expression can be controlled by Dox administration. This system for genetic manipulation could be useful for analyzing genes involved in breast cancer.

Keywords: PiggyBac, Transposon, Transgenesis, Electroporation, MaSC, Doxycycline, Tet-On system

\footnotetext{
* Correspondence: ishikawakosuke@gmail.com; ksemba@waseda.jp

${ }^{\dagger}$ Hiroaki Tagaya and Kosuke Ishikawa contributed equally to this work.

${ }^{3}$ Japan Biological Informatics Consortium (JBiC), 2-45 Aomi, Koto-ku, Tokyo

135-8073, Japan

${ }^{1}$ Department of Life Science and Medical Bioscience, School of Advanced

Science and Engineering, Waseda University, 2-2 Wakamatsu-cho,

Shinjuku-ku, Tokyo 162-8480, Japan

Full list of author information is available at the end of the article
}

(c) The Author(s). 2019 Open Access This article is distributed under the terms of the Creative Commons Attribution 4.0 International License (http://creativecommons.org/licenses/by/4.0/), which permits unrestricted use, distribution, and

reproduction in any medium, provided you give appropriate credit to the original author(s) and the source, provide a link to the Creative Commons license, and indicate if changes were made. The Creative Commons Public Domain Dedication waiver (http://creativecommons.org/publicdomain/zero/1.0/) applies to the data made available in this article, unless otherwise stated. 


\section{Background}

Most breast cancers originate from mammary epithelial cells (MECs) and progress through multiple steps. When a tumorigenic event such as gene amplification occurs [1], MECs acquire the potential to proliferate in the mammary duct and develop into ductal carcinoma in situ (DCIS) [2], which progresses to malignant carcinoma such as invasive breast carcinoma and then metastasizes into other organs through mesenchymal tissue. For in-vivo analysis of the genes involved in these processes, some genetically manipulated mouse models have been established, such as $\mathrm{TP}^{-1-} 3^{-1}$, mouse mammary tumor virus (MMTV)-neu, and MMTV-polyoma-virus middle $\mathrm{T}$ antigen (PyMT) mice. These models have boosted our understanding of the mechanisms by which mammary tumors develop and metastasize in vivo [3-5]. We have identified several oncogene candidates from amplicons of breast cancer cell lines and showed that some of the genes exhibited tumorigenic activity when gene-introduced cells were inoculated subcutaneously into nude mice [6-9]. Transgenic or knockout mouse models are useful for understanding the tumorigenic activity of those genes, but have not been practical for analyzing multiple candidate genes. Therefore, we have to establish a novel alternative method for preparing genetically engineered mice to improve the efficiency for analysis of multiple genes.

The mammary gland is a unique organ in that most mammary development occurs postnatally [10]. A small fraction of mammary stem cells (MaSCs) and progenitor cells in the basal layers of the mammary gland have regenerative capacity and maintain organ homeostasis during estrous cycles [11-17]. It has been demonstrated that the transplantation of a cell fraction with the surface markers $\mathrm{CD} 49 \mathrm{f}^{\text {high }} \mathrm{CD} 24^{+}$or $\mathrm{CD} 29^{\text {high }} \mathrm{CD} 24^{+}$into mouse fat pads from which the endogenous epithelium has been removed (cleared fat pads) can regenerate fully functional mammary gland $[12,13]$.

Harnessing this regenerative capacity of MaSCs, geneintroduced mouse mammary gland can be produced from cells enriched in MaSCs by infection with lentiviral or retroviral vectors, which is a valuable alternative approach to producing transgenic animals $[18,19]$. However, the efficiency of viral packaging has been lower when introduced genetic elements have a longer or more complicated sequence, including promoter and transcription termination sequences. In addition, to mimic the actual mechanism of tumorigenesis, the target gene is required to be inducibly expressed after mammary reconstitution.

Here, we describe a convenient method for the genetic manipulation of mouse mammary gland using a transposon vector system and electroporation. Using this method, mCherry-expressing mammary glands were first generated. The tissues were analyzed by immunostaining to examine the transgene distribution in both luminal and basal cells. Milk production during pregnancy was also examined to verify normal differentiation and mammary gland function. In addition, a vector with long DNA $(>200 \mathrm{~kb})$ derived from a bacterial artificial chromosome (BAC) clone was introduced to test its loading capacity. Moreover, using doxycycline (Dox)-inducible expression vector, we assessed the Dox-dependent expression of enhanced green fluorescent protein (EGFP) after mammary gland reconstitution. To examine whether oncogeneinduced tumorigenesis is achieved with this method, $P y M T$ was chosen for a case study and histological analyses were conducted to compare its mammary tissue with that of the MMTV-PyMT transgenic mouse model.

\section{Methods \\ Mice}

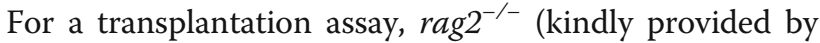
Dr. Takaki) immunocompromised albino mouse lines backcrossed with FVB or C57BL/6 J were used as recipient mice. FVB or C57BL/6 J mice were used as donors.

\section{Vector construction and preparation}

All vectors were constructed using either a ligase reaction kit (Nippon Gene, Tokyo, Japan, or Takara, Kyoto, Japan) or the In-Fusion reaction kit (Takara). In the case of long transposon donor vector loading BAC (Fig. 5a), a template vector was first constructed by joining six fragments using an In-Fusion reaction after providing each fragment with polymerase chain reaction or annealing 2 -oligo DNAs. The contents of this template vector are depicted at the bottom of Fig. 5a. Here, 70-bp and 134-bp arms homologous to the BAC vector (pBACe3.6) were placed in its flanking regions. The NotI/BstXI (FastDigest from Thermo Scientific)-digested fragment of this template vector was introduced into an $E$. coli BAC clone B6Ng01-263 N07 (RIKEN BioResource Center (BRC)) by electroporation, and a homologous recombination reaction was conducted by the RED/ET system (Gene Bridges, Heidelberg, Germany) to obtain the long transposon donor vector (Fig. 5a).

The long transposon donor vector was then purified using the NucleoBond Xtra BAC kit (Macherey-Nagel, Takara). Other vectors were purified with $\mathrm{CsCl}$-gradient ultracentrifuge sedimentation after purification with an alkaline lysis solution method.

\section{Cell culture}

Mouse embryo-derived fibroblasts, C3H10T1/2 (RCB0247; RIKEN BRC), were cultured in Dulbecco's modified Eagle's medium (DMEM; Wako Pure Chemical Industries, Ltd., Tokyo, Japan) containing 5\% fetal bovine serum (FBS), $100 \mu \mathrm{g} / \mathrm{mL}$ streptomycin sulfate (Meiji Seika Pharma, Tokyo, Japan), and $100 \mathrm{U} / \mathrm{mL}$ penicillin $\mathrm{G}$ potassium (Meiji Seika Pharma) at $37^{\circ} \mathrm{C}$ and $5 \% \mathrm{CO}_{2}$. For co-culture with MEC, C3H10T1/2 cells were treated with $4 \mu \mathrm{g} / \mathrm{mL}$ Mitomycin C 
(Wako) for $3 \mathrm{~h}$ and incubated overnight at $5 \% \mathrm{CO}_{2}$ and $37^{\circ} \mathrm{C}$ for $1-2$ days.

NMuMG cells were cultured in DMEM supplemented with $10 \% \mathrm{FBS}, 100 \mu \mathrm{g} / \mathrm{mL}$ streptomycin sulfate, $100 \mathrm{U} / \mathrm{mL}$ penicillin $\mathrm{G}$ potassium, $10 \mu \mathrm{g} / \mathrm{mL}$ insulin, and $0.45 \%$ glucose.

\section{Mammary cell preparation}

The thoracic, abdominal, and inguinal mammary glands were dissected from 8- to 10-week-old female donor mice. After washing in phosphate-buffered saline (PBS), the tissues were chopped with a razor. Then, the tissues were digested for $1-2 \mathrm{~h}$ at $37^{\circ} \mathrm{C}$ under shaking in DMEM/F12 medium (Invitrogen, Carlsbad, CA, USA) containing $5 \% \mathrm{FBS}, 2 \mathrm{mg} / \mathrm{mL}$ collagenase IV (Sigma, Poole, UK), and $0.1 \mathrm{mg} / \mathrm{ml}$ hyaluronidase (Sigma). After removing the red blood cells in DMEM/F12 by repeated low-gravity centrifugation followed by suspension in ACK buffer $\left(0.15 \mathrm{M} \mathrm{NH}_{4} \mathrm{Cl}, 10 \mathrm{mM} \mathrm{KHCO}_{3}, 0.1 \mathrm{mM}\right.$ EDTA, pH 7.3), a dissociated cell suspension was yielded by pipetting for $8-10 \mathrm{~min}$ in cell dissociation buffer (PBS, $0.05 \%$ trypsin, $0.5 \mathrm{mM}$ EDTA, 0.5\% DNaseI), and then for $2 \mathrm{~min}$ in $5 \mathrm{mg} / \mathrm{mL}$ dispase (StemCell Technologies, Vancouver, Canada) $-0.5 \%$ DNaseI, followed by filtration through a $42-\mu \mathrm{m}$ mesh.

\section{Cell sorting}

A dissociated single-cell suspension was labeled with biotinylated CD45, Ter119, CD31, and BP-1 antibodies contained in EasySep Mouse Epithelial Cell Enrichment Cocktail (StemCell Technologies) for $30 \mathrm{~min}$ on ice, and after washing, incubated with anti-CD49f-PE (eBioscience, San Diego, CA, USA), anti-CD24-perCPcy5.5 (eBioscience), streptavidin-ECD (Beckman-Coulter, Brea, CA, USA), and 7-amino-actinomycin D (7-AAD; Calbiochem, San Diego, CA, USA) for 30 min on ice. Cells were suspended in 2\% FBS-Hank's balanced salt solution including DNaseI before sorting. Cell sorting was carried out using fluorescence-activated cell sorting (FACS) SH800 (Sony, Tokyo, Japan). CD45 ${ }^{-}$Ter119- $\mathrm{CD}^{-} 1^{-} \mathrm{BP}-1^{-}$ $(\operatorname{Lin}(-)) 7-\mathrm{AAD}^{-} \mathrm{CD} 49 \mathrm{f}^{\text {high }} \mathrm{CD} 24^{+}$cells were collected to represent the MaSC-enriched fraction.

\section{Transfection}

A total of $1 \times 10^{6}$ cells of the sorted MaSC-enriched fraction from about eight mice were suspended and washed in Opti-MEM (Life Technologies, Carlsbad, CA, USA) twice. Then, $10 \mu \mathrm{g}$ of donor and helper vector DNA were mixed at a ratio of 3:1 with the MECs in OptiMEM, and subjected to electroporation using NEPA21 (NEPAGENE, Chiba, Tokyo) with a 2-mm gap electrode cuvette (NEPAGENE, EC-002S). The settings for this electroporation are shown in Additional file 1 (Table S1).
After electroporation, the cell suspension was immediately suspended in culture medium.

For transfection into NMuMG, dissociated cells were plated on six-well plates at 20-30\% confluence a day before transfection. Donor and helper vectors were introduced at an $\mathrm{OD}_{260}$ ratio of $3: 1$ by pouring the mixture of $4 \mu \mathrm{g}$ of DNA and 8-12 $\mu \mathrm{g}$ of polyethylenimine (Polysciences, Warrington, PA) into $200 \mu \mathrm{L}$ of Opti-MEM.

\section{Culture system for maintaining stemness of MaSCs}

MECs were co-cultured with mitomycin C-treated C3H10T1/2 in DMEM/F12 supplemented with $10 \%$ FBS, $10 \mathrm{ng} / \mathrm{mL}$ human epidermal growth factor (hEGF; BD Biosciences, Tokyo, Japan), $5 \mu \mathrm{g} / \mathrm{mL}$ insulin (Wako), $0.5 \mu \mathrm{g} / \mathrm{mL}$ hydrocortisone (Sigma), $5 \mu \mathrm{M}$ forskolin (Wako), $1.8 \times 10^{-4} \mathrm{M}$ adenine (Sigma), $100 \mu \mathrm{g} / \mathrm{mL}$ streptomycin (Meiji Seika Pharma), 100 U/mL penicillin G (Meiji Seika Pharma), $50 \mu \mathrm{g} / \mathrm{mL}$ gentamycin (Nakalai Tesque, Tokyo, Japan), $10 \mu \mathrm{M}$ Rho-associated coiled-coil-forming kinase inhibitor (ROCKi; Y-27632; LC Laboratories, New Boston, MA, USA) [20, 21], and 10\% Matrigel (growth factor reduced; $\mathrm{BD}$ Biosciences) at $5 \% \mathrm{CO}_{2}$ and $37^{\circ} \mathrm{C}$ for 7 days. The numbers of MECs and C3H10T1/2 were 5000 and $6.25 \times 10^{4}$, respectively, in $250 \mu \mathrm{L}$ of culture medium in a 48-well plate. When wells of different sizes were used, these numbers were changed proportionately relative to the area of the well.

\section{Transplantation assay}

The transfected MECs under culture were treated with dispase for $1-2 \mathrm{~h}$ at $37^{\circ} \mathrm{C}$ and then approximately $3 \%$ of all transfected cells were suspended in $4-10 \mu \mathrm{L}$ of DMEM/F12 including 10\% Matrigel per transplantation site and transplanted into the cleared fat pads of the inguinal mammary glands of $\mathrm{rag}^{-/-}$mice from which the endogenous epithelium had been removed using a $50-\mu \mathrm{L}$ syringe equipped with a 30-G needle (ITO, Shizuoka, Japan). Mammary repopulation was analyzed by detecting bioluminescence using an in-vivo imaging system (IVIS Lumina XR, PerkinElmer, Waltham, MA, USA) and mCherry fluorescence using a stereomicroscope (Leica, Wetzlar, Germany).

\section{Carmine alum staining}

The dissected mammary glands were spread on a glass slide and fixed using Carnoy's fixative (60\% ethanol, $30 \%$ chloroform, and $10 \%$ glacial acetic acid) overnight at room temperature. Fixed tissues were washed in $70 \%$ ethanol, gradually rehydrated to distilled $\mathrm{H}_{2} \mathrm{O}$, and then incubated in carmine alum solution $(0.2 \mathrm{wt} \%$ of carmine (Sigma) and $0.5 \mathrm{wt} \%$ of aluminum potassium sulfate (Wako) in distilled $\mathrm{H}_{2} \mathrm{O}$ ) for $2 \mathrm{~h}$ to overnight at room temperature. After gradual dehydration from $70 \%$ ethanol to $100 \%$ ethanol, fat pads were cleared overnight in xylene and mounted in MGK-S (Matsunami, Osaka, Japan). 


\section{Hematoxylin and eosin staining}

After washing in PBS, the dissected mammary glands and tumors were fixed in $4 \%$ paraformaldehyde-PBS overnight and for 2 days, respectively. After washing in PBS, samples were dehydrated gradually from $70 \%$ ethanol to $100 \%$ ethanol and then from $50 \%$ xylene in ethanol to $100 \%$ xylene, following paraffin replacement using a Leica ASP300 fully automatic closed tissue processor and paraffin-embedding using a Leica EG1160. The paraffinembedded tissues were then cut into $5-\mu \mathrm{m}$ thick sections using a Leica SM200R sliding microtome. The sections were gradually deparaffinized in xylene and then with ethanol, gradually decreasing from $100 \%$ to $50 \%$ ethanol, and washed with distilled $\mathrm{H}_{2} \mathrm{O}$, and then stained in hematoxylin solution ( $0.25 \%$ hematoxylin (Nacalai Tesque), $0.05 \%$ sodium iodate (Nacalai Tesque), $12.5 \%$ potassium alum (Wako), and $0.25 \%$ citric acid (Wako)) for $10 \mathrm{~min}$. After washing in distilled $\mathrm{H}_{2} \mathrm{O}$, sections were blued in $0.1 \%$ saturated lithium carbonate at $37{ }^{\circ} \mathrm{C}$ for $5 \mathrm{~min}$ and then washed in distilled $\mathrm{H}_{2} \mathrm{O}$ and stained in eosin solution (1\% eosin (Wako) and $0.02 \%$ glacial acetic acid) for $10 \mathrm{~min}$. After washing in $90 \%$ and $100 \%$ ethanol, sections were soaked in xylene for $5 \mathrm{~min}$ and then mounted in MGK-S (Matsunami).

\section{Immunohistochemistry}

The inguinal mammary glands were dissected, cut into $\sim 1-5-\mathrm{mm}^{3}$ fragments, and pre-fixed for $10-15 \mathrm{~min}$ in $4 \%$ paraformaldehyde-PBS on ice. Tissues were washed in cold PBS and incubated for about $1 \mathrm{~h}$ in $10 \%$ sucrose-PBS at $4{ }^{\circ} \mathrm{C}$, for about $1 \mathrm{~h}$ in $20 \%$ sucrose-PBS at $4{ }^{\circ} \mathrm{C}$, and overnight in $40 \%$ sucrose-PBS at $4{ }^{\circ} \mathrm{C}$. Tissues were frozen in cryoembedding medium [22] in liquid nitrogen. The frozen blocks were then cut into sections of 5 or $10 \mu \mathrm{m}$ thickness using a Leica CM1850 cryostat. Sections were dried for 1-10 min at room temperature, placed for more than $10 \mathrm{~min}$ in PBS, and post-fixed for $10-15 \mathrm{~min}$ in $3 \%$ paraformaldehyde at room temperature. After washing for more than 10 min in PBS or $0.1 \%$ Tween-PBS, sections were incubated in blocking buffer $(0.1 \%$ Triton/10\% goat serum in PBS) for $1 \mathrm{~h}$ at room temperature or overnight at $4{ }^{\circ} \mathrm{C}$. Staining with primary antibodies was performed overnight at $4{ }^{\circ} \mathrm{C}$ or for $1 \mathrm{~h}$ at room temperature. Then, sections were washed three times in PBS or $0.1 \%$ TweenPBS for $10 \mathrm{~min}$, and staining with secondary antibody solutions containing 4',6-diamidino-2-phenylindole (DAPI) was performed for $1 \mathrm{~h}$ at room temperature. In the case of milk fat globule (MFG) staining, sections were incubated in BODIPY 493/503 (3 $\mu \mathrm{g} / \mathrm{mL}$; Molecular Probes) containing DAPI in PBS for $10 \mathrm{~min}$ at room temperature. Then, sections were washed twice in PBS for 10 min. Finally, slides were mounted in MOWIOL DABCO.

The following primary antibodies were used: anti-KRT14 (mouse, 1:1000; Novocastra, Newcastle, UK), anti-KRT8 (rat, 1:250; Developmental Studies Hybridoma Bank, University of Iowa), anti-mCherry (rabbit, 1:250; Abcam, Cambridge, UK), and anti-PyMT (rat, 1:500; Santa Cruz, CA, USA). The following secondary antibodies were also used: anti-mouse, anti-rabbit, and anti-rat conjugated to AlexaFluor 488 (1:1000; Molecular Probes, Eugene, OR, USA) and to AlexaFluor 568 (1:1000; Molecular Probes). Staining of nuclei was performed with DAPI (1:4000; DOJINDO, Tokyo, Japan). Adjustment for the variations in the brightness and/or contrast of the entire area of images was performed using Photoshop (Adobe, San Jose, CA, USA).

\section{Immunoblotting}

Cells were collected in RIPA buffer $(10 \mathrm{mM}$ Tris- $\mathrm{HCl}$ (pH 8.0), 1\% (w/v) NP40, 0.1\% (w/v) sodium deoxycholate (Wako), 0.1\% ( $w / v)$ SDS (Wako), $0.15 \mathrm{M} \mathrm{NaCl}$ (Wako), $1 \mathrm{mM}$ EDTA, $10 \mathrm{mM} \mathrm{NaF}$ (Wako), $1.5 \mathrm{mM} \mathrm{Na} \mathrm{NO}_{4}$ (Wako), and cOmplete ${ }^{\mathrm{rm}}$ Protease Inhibitor Cocktail (Roche)). Protein concentrations were titered using the BCA protein assay kit (Thermo Fisher Scientific). Collected protein lysate was mixed with SDS-PAGE loading buffer $(0.15 \mathrm{M}$ Tris-HCl, 6\% (w/v) SDS, $0.003 \%$ (w/v) bromophenol blue (Wako), 30\% (w/v) glycerol (Wako), and $15 \%(\mathrm{w} / \mathrm{v}) \beta$-mercaptoethanol (Wako)) and then boiled at $95^{\circ} \mathrm{C}$ for $5 \mathrm{~min}$, followed by SDS-PAGE and immunoblotting. Antibodies used for immunoblotting were as follows: anti-milk (rabbit, 1:1000; Nordic-MUbio, Susteren, the Netherlands), anti-PyMT (rat, 1:500; Santa Cruz), antimCherry (rabbit, 1:500; Abcam), anti-histone H3 (rabbit, 1:2500; Cell Signaling Technology, MA, USA), and anti- $\alpha$-tubulin (mouse, 1:5000; Calbiochem).

\section{Results}

piggyBac transposon vector system and electroporation enabled us to establish gene-introduced mammary glands For the efficient establishment of gene-introduced mammary gland, we developed a convenient method combining the piggyBac transposon vector system and electroporation (Fig. 1a). The transposon vector system has recently been broadly applied as a tool for transgenesis [23], including in breast cancer research [24]. Unlike the viral vectors, the transposon vector does not need the packaging cell for vector preparation. DNA elements between the inverted terminal repeat (ITR) sequences of transposon can be integrated into the host genome via a cut-and-paste mechanism by the expression of transposase. Fairly long DNA, even 150-kb BAC, can be transferred into the host genome [25-27]. With this approach, it is particularly useful to integrate the use of the piggyBac transposon system, which allows efficient gene delivery in mammalian cells [28-30]. These features allow us to introduce a DNA sequence with a termination or promoter sequence that could be an obstacle for packaging viral vectors efficiently into 


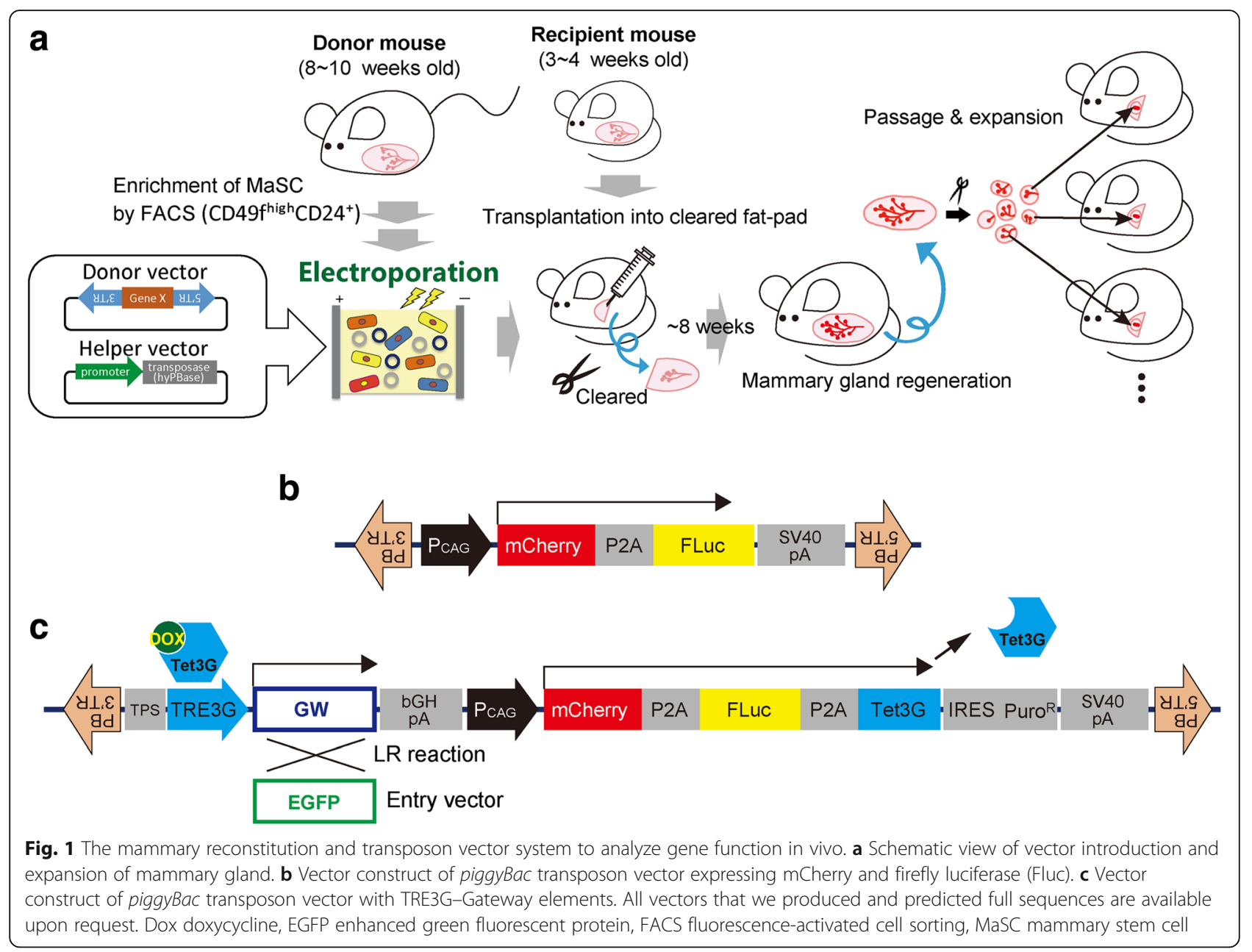

the host genome. Using electroporation, we can introduce the vectors into cells efficiently, easily, and rapidly. As an alternative to electroporation, lipofectamine is a possible option for quick and easy transfection although we have not compared these two approaches.

Here, we use the term "helper vector" to refer to a vector expressing transposase (we use a hyperactive mutant, hyPBase [29]), and use the term "donor vector" to refer to a vector having a designed DNA element between ITRs. First, two donor vectors were constructed: one expresses mCherry and firefly luciferase (Fluc) constitutively (Fig. 1b), and the other additionally expresses a gene of interest after normal mammary regeneration to mimic the actual mechanism of tumorigenesis by the Tet-On 3G system (Fig. 1c). Fluc and mCherry marker genes were placed downstream of the cytomegalovirus early enhancer/chicken $\beta$-actin (CAG) promoter that is useful for monitoring the regeneration of gene-introduced mammary glands. Under the same promoter, Tet3G gene of the Tet-On 3G system was also placed via a sequence encoding P2A peptide. TRE3G-Gateway elements, into which a gene of interest can be transferred from an ENTRY vector by a recombinase, called LR clonase, were placed on the same vector to express the gene in an inducible manner (Fig. 1c). These elements could simplify the construction of expression vectors for the genes of interest.

To produce gene-introduced mammary glands, the MaSC-enriched fraction $\left(\mathrm{CD} 49 \mathrm{f}^{\text {high }} \mathrm{CD} 24^{+}\right)$was collected by FACS from mammary glands of donor female mice aged from 8 to 10 weeks (Fig. 1a, Additional file 1: Figure S1). Then, the donor and helper vectors of the piggyBac transposon system were co-introduced into the cells using electroporation, followed by in-vitro culture. There are various approaches to maintain the stemness of MaSCs in vitro [14, 31-34], and we chose one that uses Matrigel, fibroblasts, and ROCKi (see Methods); however, it is unknown whether this is the optimal approach. To test whether the Tet-On inducible system works properly, MECs into which the TRE3G-EGFP expression vector (Fig. 1c) had been introduced by electroporation were treated Dox during the culture. mCherry-labeled MECs 
correctly inducibly expressed EGFP in a Dox-dependent manner (Additional file 1: Figure S2). The gene-introduced MECs were collected from the culture and transplanted into the cleared fat pads of the inguinal mammary glands of $\mathrm{rag}^{-/-}$mice. After 6-12 weeks, luciferase marker expression was detected using an in-vivo imaging system (IVIS) (Fig. 2a, Table 1).

In the analysis of the resected fat pads, mammary outgrowth with mCherry expression was observed (Fig. 2b). The level of luciferase expression roughly correlated with the size of the mCherry-expressing mammary glands.

To evaluate the self-renewal capacity of the gene-introduced mammary glands, one of the mCherry-expressing portions (approximately $2 \mathrm{~cm}^{2}$ ) was cut into small pieces $\left(3-5 \mathrm{~mm}^{2}\right)$, which were transplanted into newly prepared $\mathrm{rag}^{-/-}$immunocompromised mice (Fig. 1a). Outgrowth of the secondary mammary glands was observed (Fig. 2c, Table 1), suggesting that the gene-introduced mammary gland had the capacity for self-renewal. We then exposed the mice to Dox via drinking water and compared their EGFP expression to mice without Dox administration, into both of which the same branch of transgenic mammary gland had been transplanted. We observed that EGFP was expressed only in Dox-administered mice (Fig. 3), suggesting
Table 1 Frequency of regeneration of gene-introduced mammary gland

\begin{tabular}{lll}
\hline Mammary regeneration & First generation & Second generation \\
\hline First experiment & $7 / 18$ & $11 / 16$ \\
Second experiment & $3 / 18$ & $12 / 14$ \\
\hline
\end{tabular}

Mammary regeneration was judged from in-vivo imaging system analysis on the basis that $>1 \times 10^{6}$ photons/s of total flux is positive and partially from microscopic analysis on the basis of mCherry fluorescence. A fragment of primary mammary product (first generation) was dissected on day 85 (first experiment) or 105 (second experiment) after transplantation, cut into pieces, and then transplanted into the fat pad of newly prepared mice, and the secondary outgrowths (second generation) were allowed to expand for 75 (first experiment) and 28 days (second experiment)

that the gene expression can be specifically controlled in a Dox-dependent manner.

To confirm that the transgene was properly distributed to both mammary epithelial lineages, namely luminal and basal cells, we examined the tissue by histochemical analyses. We detected mCherry expression in both basal (positive for K14) and luminal (positive for K8) cell layers (Fig. 4a). In addition, pregnancy was found to result in morphological changes to the highly branched ductal and alveolar network (Fig. 4b) and the production of milk, which was assumed to occur from the detection

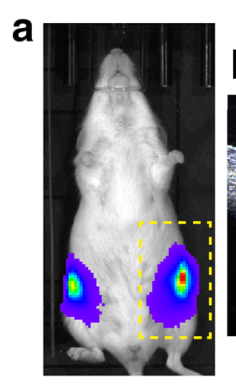

b

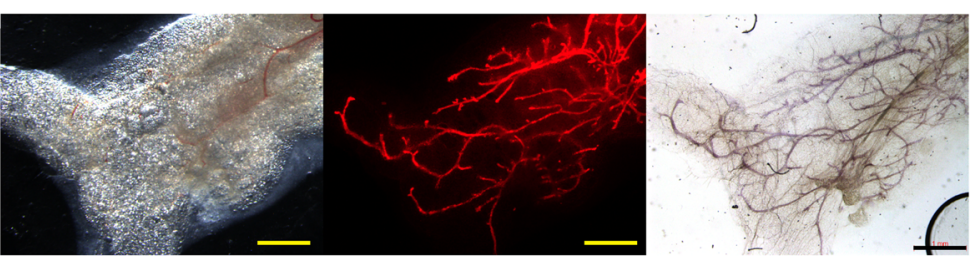

C
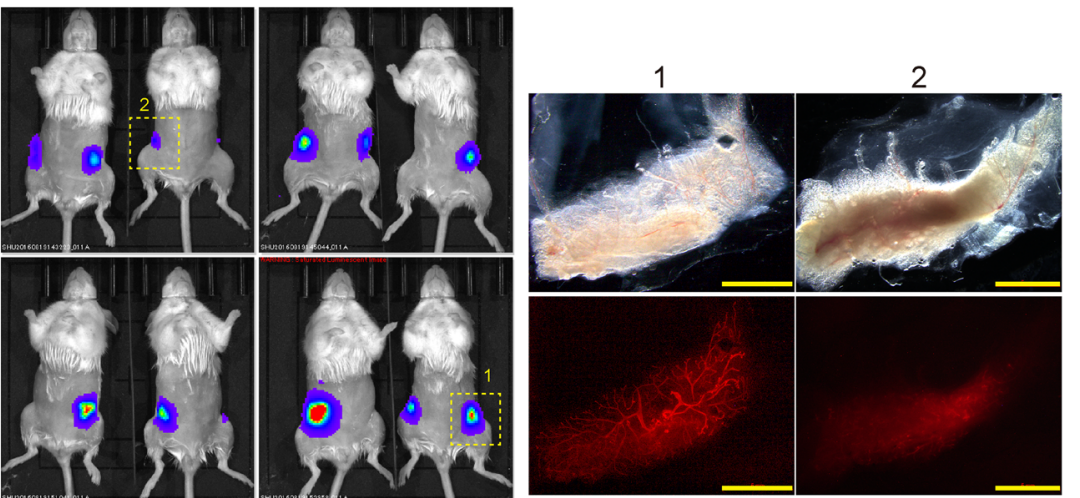

Fig. 2 Establishment of gene-introduced mammary glands. a A representative image showing luciferase activity of primary outgrowths at day 56 after mammary epithelial cell injection into cleared fat pad. b Microscopic view of resected fat pads from $\mathbf{a}$. Red fluorescence (middle panel) shows mCherry marker expression. Right panel shows carmine staining to show whole mammary glands in this fat pad. Scale bar $=1 \mathrm{~mm}$. $\mathbf{c}$ IVIS images of secondary outgrowth at day 75 after transplantation of mCherry-expressing fragments of one primarily reconstituted mammary gland. Right panels are microscopic images of the dissected mammary gland from the site indicated by the yellow dotted boxes in the left images. Lower panels show mCherry marker expression. Scale bars $=5 \mathrm{~mm}$ 


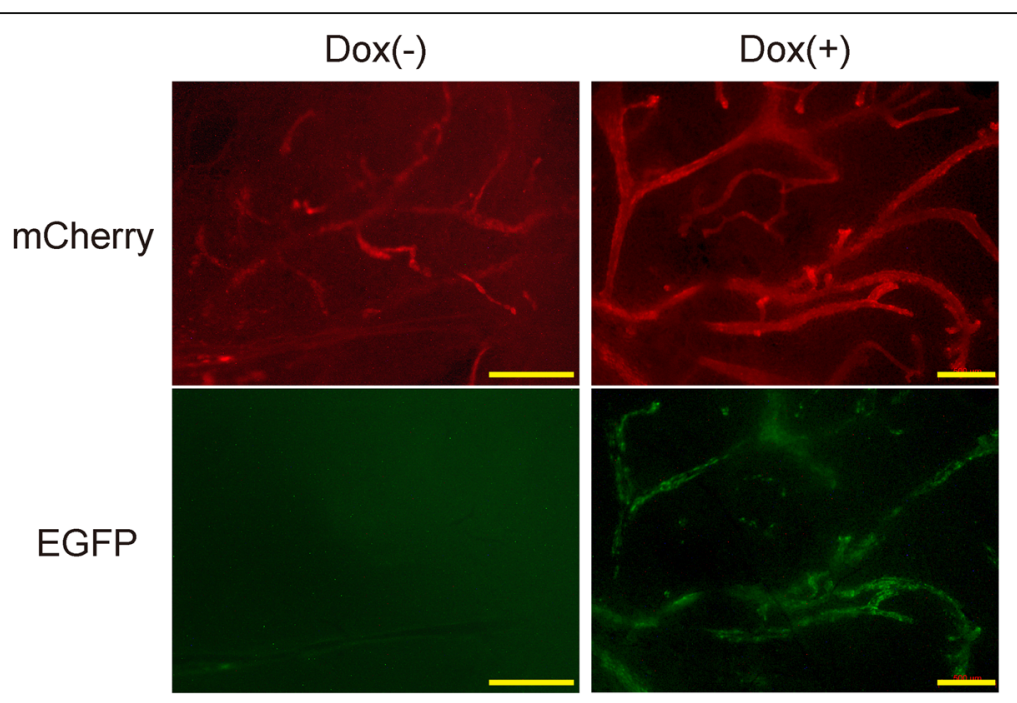

Fig. 3 Dox-dependent expression of the TRE3G-EGFP-introduced mammary gland. Mice from Fig. 2c were exposed to doxycycline (Dox) (right) via drinking water for 55 days and compared to mice not administered Dox (left). Scale bars $=500 \mu \mathrm{m}$. EGFP enhanced green fluorescent protein

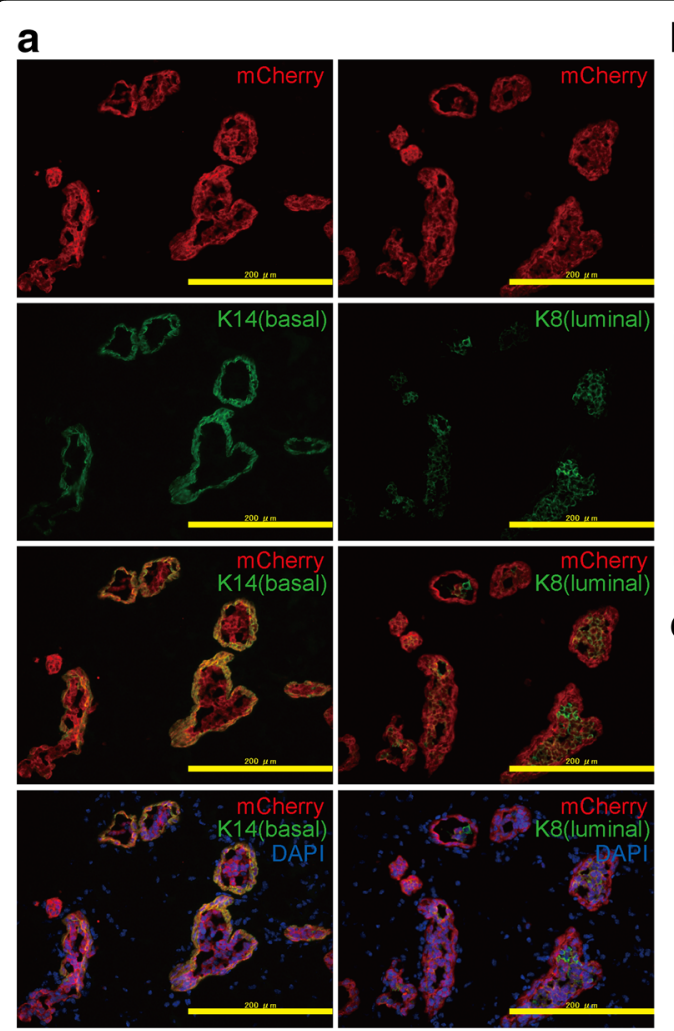

b

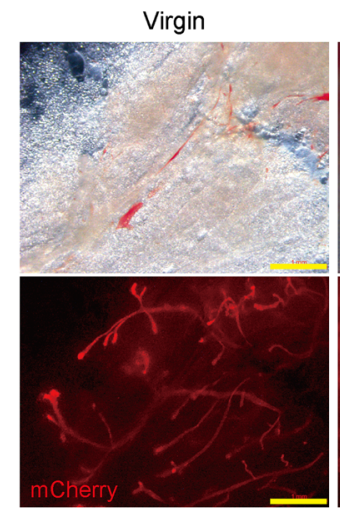

C

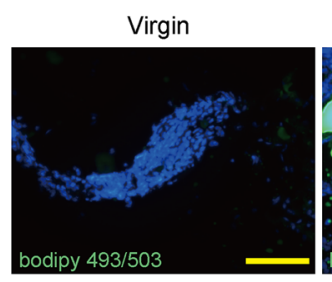

d

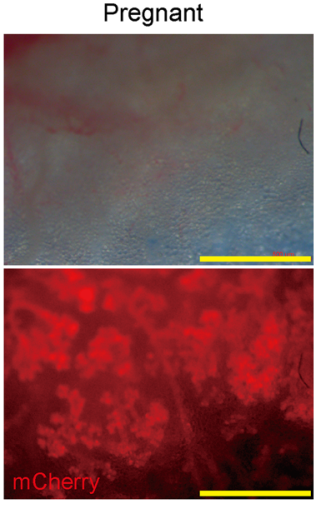

Pregnant

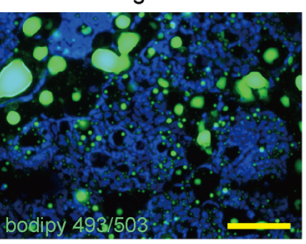

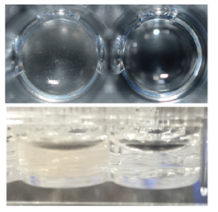

$\mathbf{e}$

Vector introduced Wild type mammary gland control

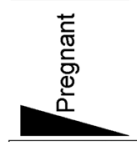

들

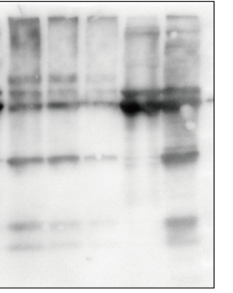

Anti-

histone

$\mathrm{H} 3$

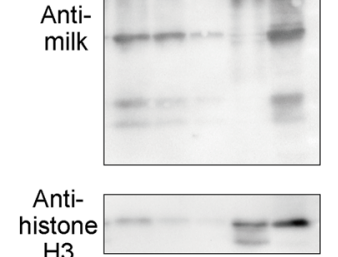

Fig. 4 Analyses of the differentiation and function of gene-introduced mammary glands. a Lineage distribution of gene-introduced MECs. Co-immunostaining of mCherry (red, upper panels) in combination with K14 (basal marker, green, left panels) or K8 (luminal marker, green, right panels) in pregnant mice. Scale bars $=200 \mu \mathrm{m}$. b Gene-introduced outgrowths in virgin (left panels) and pregnant mice (right panels). Red fluorescence (lower panels) represents mCherry expression. Scale bars $=1 \mathrm{~mm}$. c Analysis of milk production by staining of lipid droplets (BODIPY 493/503) of gene-introduced mammary glands during pregnancy (right panel). Left panel shows control staining of virgin mammary glands. Scale bars $=200 \mu \mathrm{m}$. $\mathbf{d}$ Turbid secretory components were observed upon the immersion of dissected regenerative mammary gland of pregnant mice in PBS (left). Right shows PBS control. e Immunoblot analysis of indicated lysates derived from virgin or pregnant mammary glands. Histone H3 represents internal control. DAPI 4',6-diamidino-2-phenylindole 
of MFGs (Fig. 4c), opacity of secretory components (Fig. 4d), and the same pattern of milk protein as wild-type pregnant mammary gland (Fig. 4e).

These observations confirmed that the gene-introduced mammary glands exhibited normal differentiation potential and were fully functional.

\section{The piggyBac transposon vector system had a high} capacity for loading long DNA elements (> $200 \mathrm{~kb}$ ) Viral vector systems have a length restriction for carrying or packaging a gene (maximum of $\sim 10 \mathrm{~kb}$ ), whereas transposon vectors have a much higher capacity [25-27]. We investigated whether the length restriction of viral vector systems can be overcome by our piggyBac transposon vector system. We constructed a donor vector that can load DNA elements from a BAC clone (B6Ng01-263 N07) obtained from RIKEN BRC, whose vector size was > $200 \mathrm{~kb}$ (Fig. 5a). When we introduced this vector into an MaSC-enriched fraction using electroporation, cultured MECs expressed mCherry fluorescence (Fig. 5b). In addition, outgrowth of BAC-introduced mammary glands was detected in vivo and ex vivo based on Fluc and mCherry marker gene expression, respectively (Fig. 5c, d). This suggested that our vector system can deliver much larger cargo into cells compared with conventional viral vector systems.

\section{PyMT oncogene expression in mammary glands phenocopied the MMTV-PyMT transgenic mouse model} We next investigated whether our vector system could phenocopy a transgenic mouse model of breast cancer. It is known that mice that express PyMT under control of the MMTV promoter develop hyperplasias, which progress to adenocarcinoma $[35,36]$. We designed the piggyBac transposon vector, which can express PyMT by the addition of Dox using Tet3G of Tet-On system that exhibits expression under the control of the MMTV promoter (Fig. 6a).

To check whether the inducible expression vector for PyMT functions properly, we transfected it into NMuMG cells and analyzed the protein expression by immunoblotting. To activate MMTV promoter in NMuMG cells, a synthetic glucocorticoid, dexamethasone (Dex), was added into the culture medium [37]. As expected, Dex- and Dox-dependent PyMT upregulation was observed (Fig. 6b). It was also observed that PyMT was weakly expressed without the addition of Dox (lanes 2 and 6).

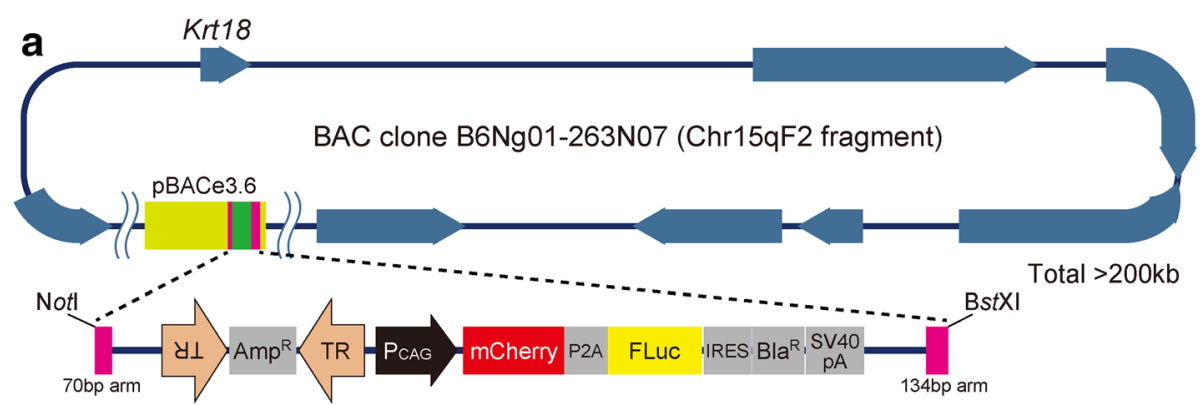

b

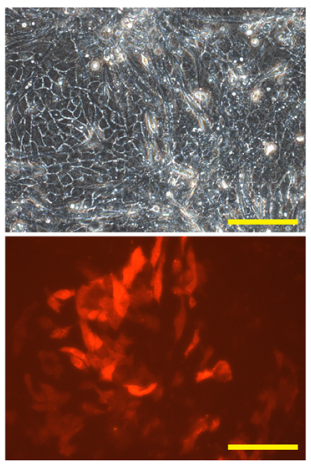

C

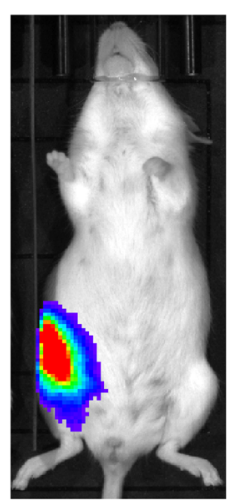

d
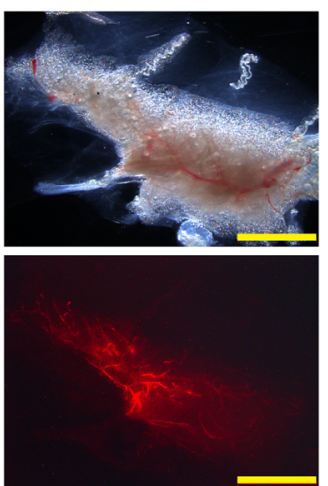

Fig. 5 High loading capacity of the piggyBac donor vector for reconstitution of vector-introduced mammary glands. a Map of piggyBac transposon donor vector carrying long a DNA (approximately $200 \mathrm{~kb}$ ) derived from a bacterial artificial chromosome (BAC) vector (RIKEN B6Ng01-263 N07) containing a fragmentary mouse genomic sequence encompassing at least eight known genes including Krt18. b Microscopic view of the BAC vector-introduced MECs. Red fluorescence (lower panels) shows mCherry marker driven by CAG promoter. Scale bar $=100 \mu \mathrm{m}$. c A representative image showing luciferase activity of mammary outgrowths at day 50 after mammary epithelial cell injection into cleared fat pad. $\mathbf{d}$ Microscopic view of resected fat pads from $\mathbf{c}$. Red fluorescence (lower panels) shows mCherry marker expression. Scale bar $=5 \mathrm{~mm}$ 

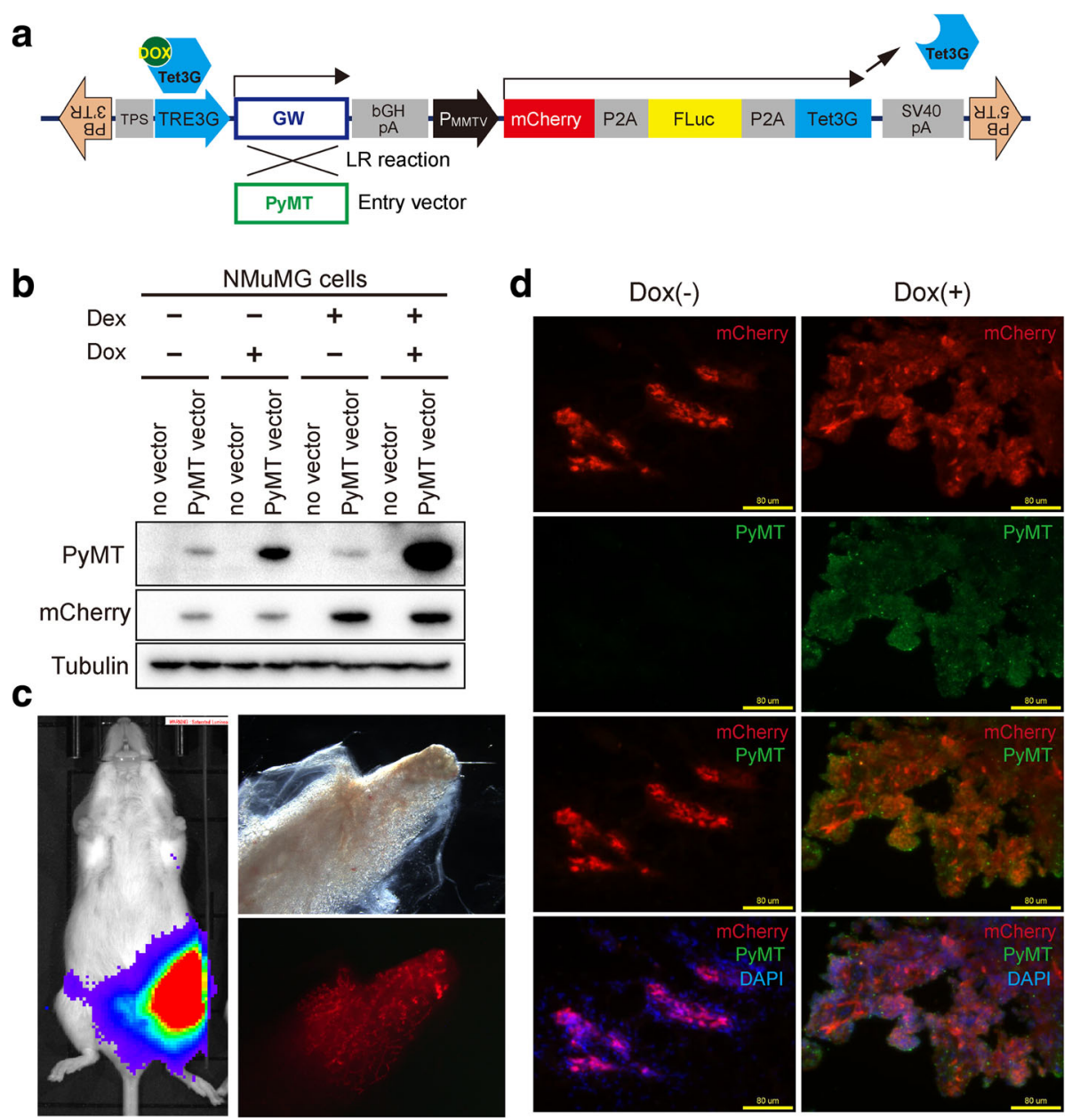

Fig. 6 Establishment of PyMT oncogene-introduced mammary glands. a Vector construct of piggyBac transposon donor vector expressing mCherry, firefly luciferase (FLuc), and Tet3G under the control of the mouse mammary tumor virus (MMTV) promoter. Polyoma-virus middle T antigen (PYMT) was introduced downstream of TRE3G using LR recombinase of the Gateway system. $\mathbf{b}$ Immunoblot analysis of indicated lysates derived from NMUMG cells not transfected or transfected with TRE-PyMT vector. Tubulin represents internal control. c (left panel) A representative image showing luciferase activity of mammary outgrowths at day 42 after mammary epithelial cell injection into cleared fat pad. (Right panels) Microscopic view of resected fat pads. Red fluorescence (lower panel) shows mCherry marker expression. Scale bar $=5 \mathrm{~mm}$. $\mathbf{d}$ Analysis of PyMT expression by immunofluorescence staining. Frozen sections from TRE-PyMT-introduced mammary glands passaged from a primarily reconstituted gland without Dox (right panels) and with Dox (left panels) in drinking water were co-immunostained with antibodies against mCherry (red, upper panels) and PyMT (green). Scale bars = $80 \mu \mathrm{m}$. DAPI 4',6-diamidino-2-phenylindole, Dex dexamethasone, Dox doxycycline

We transduced PyMT vector into MaSC-enriched MECs (Fig. 6c) and passaged its reconstituted tissues about 2 months after primary transplantation. The secondary transplanted mice were fed with drinking water with or without doxycycline 2-3 weeks after transplantation for about 3 months. In histochemical analyses of the dissected tissues, we detected the co-expression of PyMT with mCherry (Fig. 6d) and morphological changes that were highly similar to those of tissues from MMTV-PyMT transgenic mice (Fig. 7a-c). The adenoma and carcinoma-like phenotype depended on PyMT expression levels observed in Fig. 6b; namely, a weak phenotype was observed on leaky-level expression $(\operatorname{Dox}(-))$ or a strong phenotype on high expression $(\operatorname{Dox}(+))$. These results demonstrated that the novel method that we developed provides a promising alternative to producing transgenic mice.

\section{Discussion}

The mouse mammary gland provides a unique model for the study of MaSCs and differentiation pathways and pathogenesis of breast cancer [38-40]. Recent studies of cellular hierarchical issues using mammary glands have contributed to better understanding of "cells of origin" and "cancer stem cells" with regard to breast cancer [5, 40-43]. Breast cancer occurs when genetic mutations occur during tissue development. Transgenic and knockout mouse models have been used in previous studies involving genetic analysis. By several in vitro, allograft, 

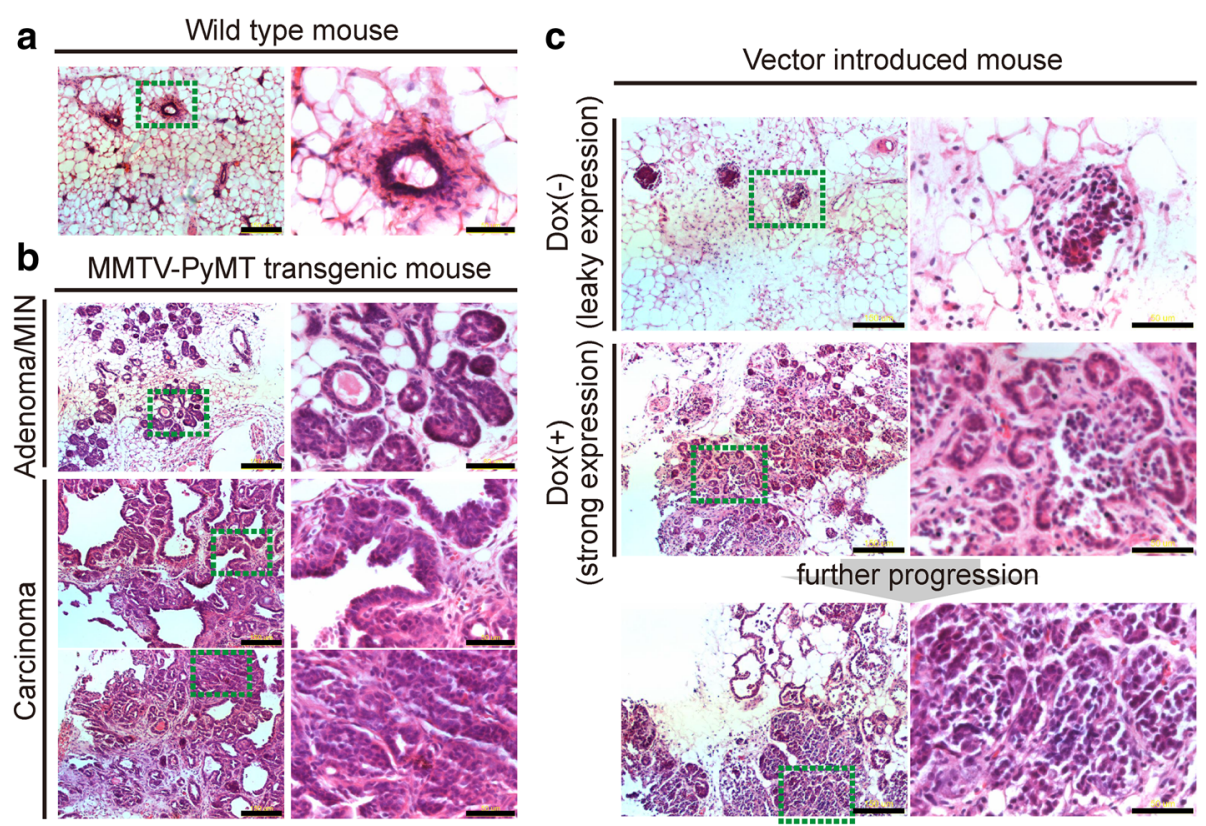

Fig. 7 Analysis of the histochemical properties of the oncogene-induced mammary glands. Images of hematoxylin and eosin staining of paraffin sections of $\mathbf{a}$ normal and $\mathbf{b}$ mouse mammary tumor virus-polyoma-virus middle T antigen (MMTV-PyMT) transgenic mouse mammary glands. Scale bars $=150 \mu \mathrm{m}$ (left panels) and $50 \mu \mathrm{m}$ (right panels). The right panels represent a higher resolution image corresponding to the green dotted square in the left panels. $\mathbf{c}$ Representative images of hematoxylin and eosin staining of paraffin sections of TRE-PyMT-introduced mammary glands fed without doxycycline (Dox) (upper panels) or with Dox (middle panels). The right panels represent a higher resolution image corresponding to the green dotted square in the left panels. The lower panels show one of the progressed tumors derived from the same tissue as shown in the upper panels. Scale bars $=150 \mu \mathrm{m}$ (left panels) and $50 \mu \mathrm{m}$ (right panels)

and xenograft screenings and analyses of microarray data, we found multiple candidate genes and hoped to evaluate their oncogenic or malignant phenotypes in vivo on mammary epithelium at specific differentiation phases [6-9]. For practicality of this situation, an alternative method needs to be developed for producing genetically manipulated mammary glands with ease and rapidity. Combined with piggyBac transposon vector system and electroporation, we obtained genetically manipulated mammary gland in 2-3 months. Although, the reconstitution efficiency of the first genetically manipulated mammary gland was low (3/18 to $7 / 18)$ (Table 1$)$, secondary transplantation after cutting the first reconstituted mammary glands into small pieces and selecting gene-introduced mammary gland using the mCherry fluorescence marker yielded successful expansion with high efficiency (11/16 to $12 / 14$ from one regenerated mammary gland). This property is highly useful for statistical analyses or maintenance of mammary tissue lines. Doxycycline-dependent change in expression levels was successfully achieved in a case where an EGFP- or PyMTinducible expression cassette was used in the vector. In future studies, we hope to apply this tool to candidate genes that may confer malignant phenotypes and evaluate their in-vivo function during the development of mammary gland. By using IVIS, events such as metastasis can be monitored by our vector system. In addition, the expression promoter presented here can be modified depending on the purpose of the particular research. For example, by utilizing the K8 or K14 promoter, lineage-specific expression control in luminal or basal cells, respectively, can be achieved. In addition, it is also possible to establish a gene suppression system by introducing CRISPR-Cas9 or a knockdown approach. These modifications are easily achieved thanks to the use of the transposon donor vector backbone, which has almost no limitation concerning DNA complexity (termination or promoter sequence) and length. Actually, our system enabled us to produce a mammary gland into which a BAC vector was integrated whose vector size was $>200 \mathrm{~kb}$ (Fig. 5), suggesting the possibility of using genomic DNA elements of almost unlimited length for gene transduction. Thus, the presented methods and tools may be broadly applicable and open a new avenue for breast cancer research.

\section{Conclusions}

With our system presented here, gene transduction into mammary gland in vivo can be easily and quickly achieved and gene expression can be controlled by administering doxycycline. This system for genetic manipulation is potentially useful for analyzing genes involved in breast cancer. 


\section{Additional file}

Additional file 1: Table S1. Electroporation parameters obtained by NEPA21 electroporator (NEPAGENE) for gene transduction into MaSC-enriched cells. Figure S1. Isolation of basal/MaSC fraction from female mice aged 8-10 weeks. a Singlet sorting. b Further singlet sorting. $\mathbf{c} \operatorname{Lin}(-)$ 7-AAD(-) sorting, excluding hematopoietic, endothelial, and stromal cells (Lin(+)), and dead cells $(7-A A D(+))$. $\mathbf{d}$ Sorting of basal/MaSC fraction by CD49f and CD24. Figure S2. Dox-dependent expression of TRE3G-EGFP gene-introduced MECs under MMF culture. Red fluorescence shows mCherry marker driven by

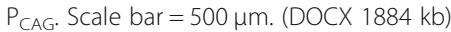

\section{Abbreviations}

7-AAD: 7-Amino-actinomycin D; BAC: Bacterial artificial chromosome; CAG: Cytomegalovirus early enhancer/chicken $\beta$-actin; DAPI: 4',6-Diamidino2-phenylindole; Dex: Dexamethasone; DMEM: Dulbecco's modified Eagle's medium; Dox: Doxycycline; EGFP: Enhanced green fluorescent protein; FACS: Fluorescence-activated cell sorting; FBS: Fetal bovine serum; Fluc: Firefly luciferase; ITR: Inverted terminal repeat; IVIS: In-vivo imaging system; MaSC: Mammary stem cell; MEC: Mammary epithelial cell; MFG: Milk fat globule; MMTV: Mouse mammary tumor virus; PBS: Phosphate-buffered saline; PyMT: Polyoma-virus middle T antigen; ROCKi: Rho-associated coiledcoil-forming kinase inhibitor

\section{Acknowledgments}

We thank all laboratory members who supported the maintenance and breeding of mice, without whom the experiments would not have been successful. We are also grateful to Dr. Allan Bradley and Dr. Kosuke Yusa (the Wellcome Trust Sanger Institute) for providing piggyBac transposon's backbone donor vectors [44] and a hyPBase vector [29], Dr. Keiji Miyazawa (University of Yamanashi in Japan) for NMuMG cells, Dr. Satoshi Takaki (National Center for Global Health and Medicine in Japan) for the rag2 ${ }^{-1-}$ mouse line, and Dr. Takeharu Sakamoto (IMSUT) for tissue samples of MMTV-PyMT transgenic mice. The authors would like to thank Enago (https://www.enago.jp) for the English language review.

\section{Funding}

This study was supported in part by grants for translational research programs from Fukushima Prefecture and from MEXT/JSPS KAKENHI (grant numbers 23241064, 25670100, and 15 K15022), and by the MEXT-Supported Program for the Strategic Research Foundation at Private Universities. Japan Biological Informatics Consortium also provided funding to cover the open access charge.

\section{Availability of data and materials}

The experimental data generated and/or analyzed during this study are available from the corresponding author on reasonable request. All vectors that we produced and predicted full sequences are also available upon request.

\section{Authors' contributions}

HT and KI drafted the manuscript with KeS. KI designed all of the experiments with KeS, and all of the vectors, with help from NG. YU constructed the donor vector from BAC. HT, KI, YH, SK, YU, and MS established gene-introduced mammary glands. HT, YU, and MS analyzed the tissue samples. MY, TI, KK, KoS, HM, and YO conducted preliminary experiments, established mouse experiments, and helped reach the conclusions of this study. SW assisted in flow cytometric and IVIS analyses. All authors read and approved the final manuscript.

\section{Ethics approval}

All genetic and animal studies were approved by the ethics committee of Waseda University (WD17-083, 2017-A042).

\section{Consent for publication}

Not applicable.

\section{Competing interests}

The authors declare that they have no competing interests.

\section{Publisher's Note}

Springer Nature remains neutral with regard to jurisdictional claims in published maps and institutional affiliations.

\section{Author details}

${ }^{1}$ Department of Life Science and Medical Bioscience, School of Advanced Science and Engineering, Waseda University, 2-2 Wakamatsu-cho, Shinjuku-ku, Tokyo 162-8480, Japan. ${ }^{2}$ Computational Bio Big-Data Open Innovation Laboratory (CBBD-OIL), National Institute of Advanced Industrial Science and Technology (AIST), 3-4-1 Okubo, Shinjuku-ku, Tokyo 169-8555, Japan. ${ }^{3}$ Japan Biological Informatics Consortium (JBiC), 2-45 Aomi, Koto-ku, Tokyo 135-8073, Japan. ${ }^{4}$ Division of Cellular and Molecular Biology, The Institute of Medical Science, The University of Tokyo, Tokyo, Japan. ${ }^{5}$ National Institute of Advanced Industrial Science and Technology (AIST), Koto-ku, Tokyo 135-0064, Japan. ${ }^{6}$ Translational Research Center, Fukushima Medical University, Hikarigaoka, Fukushima 960-1295, Japan.

Received: 8 October 2018 Accepted: 5 December 2018

Published online: 05 January 2019

\section{References}

1. Matsui A, Ihara T, Suda H, Mikami H, Semba K. Gene amplification: mechanisms and involvement in cancer. Biomol Concepts. 2013;4:567-82.

2. Vargo-Gogola T, Rosen JM. Modelling breast cancer: one size does not fit all. Nat Rev Cancer. 2007;7:659-72.

3. Cicalese A, Bonizzi G, Pasi CE, Faretta M, Ronzoni S, Giulini B, et al. The tumor suppressor p53 regulates polarity of self-renewing divisions in mammary stem cells. Cell. 2009;138:1083-95.

4. DeNardo DG, Barreto JB, Andreu P, Vasquez L, Tawfik D, Kolhatkar N, et al. CD4(+) T cells regulate pulmonary metastasis of mammary carcinomas by enhancing protumor properties of macrophages. Cancer Cell. 2009;16:91-102.

5. Molyneux G, Geyer FC, Magnay FA, McCarthy A, Kendrick H, Natrajan R, et al. BRCA1 basal-like breast cancers originate from luminal epithelial progenitors and not from basal stem cells. Cell Stem Cell. 2010;7:403-17.

6. Saito M, Kato $Y$, Ito E, Fujimoto J, Ishikawa K, Doi A, et al. Expression screening of 17q12-21 amplicon reveals GRB7 as an ERBB2-dependent oncogene. FEBS Lett. 2012:586:1708-14.

7. Doi A, Ishikawa K, Shibata N, Ito E, Fujimoto J, Yamamoto M, et al. Enhanced expression of retinoic acid receptor alpha (RARA) induces epithelial-tomesenchymal transition and disruption of mammary acinar structures. Mol Oncol. 2015;9:355-64.

8. Matsui A, Fujimoto J, Ishikawa K, Ito E, Goshima N, Watanabe S, et al. Hepatocyte nuclear factor 1 beta induces transformation and epithelial-tomesenchymal transition. FEBS Lett. 2016:590:1211-21.

9. Ihara T, Hosokawa Y, Kumazawa K, Ishikawa K, Fujimoto J, Yamamoto M, et al. An in vivo screening system to identify tumorigenic genes. Oncogene. 2017;36:2023-9.

10. Asselin-Labat ML, Sutherland KD, Barker $H$, Thomas $R$, Shackleton M, Forrest NC, et al. Gata-3 is an essential regulator of mammary-gland morphogenesis and luminal-cell differentiation. Nat Cell Biol. 2007:9:201-9.

11. Deome KB, Faulkin $L J J$ r, Bern HA, PB B. Development of mammary tumors from hyperplastic alveolar nodules transplanted into gland-free mammary fat pads of female C3H mice. Cancer Res. 1959;19:515-20.

12. Shackleton M, Vaillant F, Simpson KJ, Stingl J, Smyth GK, Asselin-Labat ML, et al. Generation of a functional mammary gland from a single stem cell. Nature. 2006;439:84-8.

13. Stingl J, Eirew P, Ricketson I, Shackleton M, Vaillant F, Choi D, et al. Purification and unique properties of mammary epithelial stem cells. Nature. 2006:439:993-7

14. Prater MD, Petit V, Alasdair Russell I, Giraddi RR, Shehata M, Menon S, et al. Mammary stem cells have myoepithelial cell properties. Nat Cell Biol. 2014; 16:942-50 1-7.

15. Van Keymeulen A, Rocha AS, Ousset M, Beck B, Bouvencourt G, Rock J, et al. Distinct stem cells contribute to mammary gland development and maintenance. Nature. 2011;479:189-93.

16. Asselin-Labat ML, Vaillant F, Sheridan JM, Pal B, Wu D, Simpson ER, et al. Control of mammary stem cell function by steroid hormone signalling. Nature. 2010;465:798-802.

17. Joshi PA, Jackson HW, Beristain AG, Di Grappa MA, Mote PA, Clarke CL, et al. Progesterone induces adult mammary stem cell expansion. Nature. 2010; 465:803-7. 
18. Welm BE, Dijkgraaf GJ, Bledau AS, Welm AL, Werb Z. Lentiviral transduction of mammary stem cells for analysis of gene function during development and cancer. Cell Stem Cell. 2008;2:90-102.

19. Bouras T, Pal B, Vaillant F, Harburg G, Asselin-Labat ML, Oakes SR, et al. Notch signaling regulates mammary stem cell function and luminal cell-fate commitment. Cell Stem Cell. 2008;3:429-41.

20. Watanabe K, Ueno M, Kamiya D, Nishiyama A, Matsumura M, Wataya T, et al. A ROCK inhibitor permits survival of dissociated human embryonic stem cells. Nat Biotechnol. 2007;25:681-6.

21. Kurosawa H. Application of Rho-associated protein kinase (ROCK) inhibitor to human pluripotent stem cells. J Biosci Bioeng. 2012;114:577-81.

22. Cocco C, Melis GV, Ferri GL. Embedding media for cryomicrotomy: an applicative reappraisal. Appl Immunohistochem Mol Morphol. 2003;11:274-80.

23. Ivics Z, Li MA, Mates L, Boeke JD, Nagy A, Bradley A, et al. Transposonmediated genome manipulation in vertebrates. Nat Methods. 2009;6:415-22.

24. Khaled WT, Choon Lee S, Stingl J, Chen X, Raza Ali H, Rueda OM, et al. $\mathrm{BCL} 11 \mathrm{~A}$ is a triple-negative breast cancer gene with critical functions in stem and progenitor cells. Nat Commun. 2015;6:5987.

25. Suster ML, Sumiyama K, Kawakami K. Transposon-mediated BAC transgenesis in zebrafish and mice. BMC Genomics. 2009;10:477.

26. Li MA, Turner DJ, Ning Z, Yusa K, Liang Q, Eckert $\mathrm{S}$, et al. Mobilization of giant piggyBac transposons in the mouse genome. Nucleic Acids Res. 2011; 39:e148.

27. Rostovskaya M, Fu J, Obst M, Baer I, Weidlich S, Wang H, et al. Transposonmediated BAC transgenesis in human ES cells. Nucleic Acids Res. 2012;40:e150.

28. Wu SC, Meir YJ, Coates CJ, Handler AM, Pelczar P, Moisyadi S, et al. piggyBac is a flexible and highly active transposon as compared to sleeping beauty, Tol2, and Mos1 in mammalian cells. Proc Natl Acad Sci U S A. 2006;103:15008-13.

29. Yusa K, Zhou L, Li MA, Bradley A, Craig NL. A hyperactive piggyBac transposase for mammalian applications. Proc Natl Acad Sci U S A. 2011;108:1531-6.

30. Yusa K. piggyBac transposon. Microbiol Spectr. 2015;3:MDNA3-0028-2014.

31. Makarem M, Kannan N, Nguyen LV, Knapp DJ, Balani S, Prater MD, et al. Developmental changes in the in vitro activated regenerative activity of primitive mammary epithelial cells. PLoS Biol. 2013;11:e1001630.

32. Spike BT, Engle DD, Lin JC, Cheung SK, La J, Wahl GM. A mammary stem cell population identified and characterized in late embryogenesis reveals similarities to human breast cancer. Cell Stem Cell. 2012;10:183-97.

33. Dong Q, Wang D, Bandyopadhyay A, Gao H, Gorena KM, Hildreth K, et al. Mammospheres from murine mammary stem cell-enriched basal cells: clonal characteristics and repopulating potential. Stem Cell Res. 2013;10: 396-404.

34. Zhang Z, Christin JR, Wang C, Ge K, Oktay MH, Guo W. Mammary-stem-cellbased somatic mouse models reveal breast cancer drivers causing cell fate dysregulation. Cell Rep. 2016;16:3146-56.

35. Fluck MM, Schaffhausen BS. Lessons in signaling and tumorigenesis from polyomavirus middle T antigen. Microbiol Mol Biol Rev. 2009;73:542-63 Table of Contents.

36. Lin EY, Jones JG, Li P, Zhu L, Whitney KD, Muller WJ, et al. Progression to malignancy in the polyoma middle T oncoprotein mouse breast cancer model provides a reliable model for human diseases. Am J Pathol. 2003;163: 2113-26.

37. Cato AC, Miksicek R, Schutz G, Arnemann J, Beato M. The hormone regulatory element of mouse mammary tumour virus mediates progesterone induction. EMBO J. 1986;5:2237-40.

38. Smith GH. Experimental mammary epithelial morphogenesis in an in vivo model: evidence for distinct cellular progenitors of the ductal and lobular phenotype. Breast Cancer Res Treat. 1996;39:21-31.

39. Jeselsohn R, Brown NE, Arendt L, Klebba I, Hu MG, Kuperwasser C, et al. Cyclin D1 kinase activity is required for the self-renewal of mammary stem and progenitor cells that are targets of MMTV-ErbB2 tumorigenesis. Cancer Cell. 2010;17:65-76.

40. Visvader JE, Stingl J. Mammary stem cells and the differentiation hierarchy: current status and perspectives. Genes Dev. 2014;28:1143-58.

41. Stingl J, Caldas C. Molecular heterogeneity of breast carcinomas and the cancer stem cell hypothesis. Nat Rev Cancer. 2007;7:791-9.

42. Visvader JE. Cells of origin in cancer. Nature. 2011;469:314-22.

43. Keller PJ, Arendt LM, Skibinski A, Logvinenko T, Klebba I, Dong S, et al. Defining the cellular precursors to human breast cancer. Proc Natl Acad Sci U S A. 2012;109:2772-7.

44. Cadinanos J, Bradley A. Generation of an inducible and optimized piggyBac transposon system. Nucleic Acids Res. 2007;35:e87.

\section{Ready to submit your research? Choose BMC and benefit from:}

- fast, convenient online submission

- thorough peer review by experienced researchers in your field

- rapid publication on acceptance

- support for research data, including large and complex data types

- gold Open Access which fosters wider collaboration and increased citations

- maximum visibility for your research: over $100 \mathrm{M}$ website views per year

At $\mathrm{BMC}$, research is always in progress.

Learn more biomedcentral.com/submissions 